\title{
O CASO POLICIAIS CIVIS NO DOI/CODI/II EXÉRCITO E A JUSTIÇA DE TRANSIÇÃO: BREVE REFLEXÃO SOBRE POSSIBILIDADES DE REFORMA DAS INSTITUIÇÕES DE SEGURANÇA ${ }^{12}$
}

\author{
Diego Oliveira de Soura ${ }^{3}$
}

\begin{abstract}
Resumo
Este artigo trata de estudo acerca do Caso Policiais Civis no DOI/CODI/II Exército e sua relação com o desenvolvimento do campo da justiça de transição no Brasil. Seu objetivo central é apontar possibilidades de reforma das instituições de segurança no Brasil, envolvidas na prática sistemática de violações de direitos humanos durante a Ditadura Civil-Militar, a partir da atuação de 3 delegados da Polícia Civil do Estado de São Paulo, no DOI/CODI/II Exército, como destacados agentes da repressão política apontados em episódios de tortura, desaparecimentos forçados e mortes, durante a década de 1970. A hipótese desenvolvida no artigo trata da manifestação de ideias de justiça dominantes no julgamento dos crimes praticados por agentes da repressão política. Constituído por meio de levantamento bibliográfico e de fontes documentais judiciais e extrajudiciais, parte do marco analítico da justiça de transição, a fim de compreender o julgamento cível em primeira instância do caso estudado. Entre as conclusões deste artigo, destaca-se a necessidade de promoção de medidas de justiça transição, concernentes aos expurgos de agentes da repressão política, ainda pertencentes aos quadros da Polícia Civil do Estado de São Paulo, bem como à desconstituição de vínculos funcionais daqueles agentes repressores com o Estado, para se possibilitar a reforma institucional da Polícia Civil do Estado de São Paulo, marcada pela impunidade de seus agentes envolvidos na prática de crimes de Estado durante a Ditadura Civil-Militar.
\end{abstract}

Palavras-chave: Policiais Civis. DOI/CODI/II Exército. Justiça de Transição. Reforma das Instituições.

\begin{abstract}
This article deals with study of the case in the Civil Police DOI/CODI/II Army and its relationship to the development of transitional justice field in Brazil. Your main objective is to point security institutions reform possibilities in Brazil, involved in the systematic practice of human rights violations during the Civil-Military Dictatorship, from the performance of three delegates of the State Civil Police of São Paulo in DOI/CODI/II Army as outstanding agents of political repression aimed in episodes of torture, enforced disappearances and deaths during the 1970s The hypothesis developed in the article deals with the manifestation of the dominant ideas of justice in the trial of crimes committed by agents of repression policy. Constituted through literature and judicial and extrajudicial documentary sources, part of the analytical framework of transitional justice in order to understand the civil trial in first instance of the case study. Among the conclusions of this article, it highlights the need to promote justice measures transition, concerning the purges of political repression agents, still belonging to the staff of the State Civil Police of São Paulo, as well as deconstitution functional linkages those agents repressors with the State, to enable the institutional reform of the Civil Police of São Paulo, marked by the impunity of the agents involved in the practice of state crimes during the Civil-Military Dictatorship.
\end{abstract}

Keywords: Civil Police. DOI/CODI/II Army. Transitional Justice. Institutional Reform.

\footnotetext{
${ }^{1}$ DOI deste artigo: $10.5380 /$ recp.v6i2.42524.

2 O presente artigo é uma versão revisada e ampliada da comunicação apresentada no II Encontro de Pesquisas Históricas - EPHIS, realizado na Pontifícia Universidade Católica do Rio Grande do Sul (PUC-RS), em Porto Alegre, entre os dias 26 e 28 de maio de 2015.

${ }^{3}$ Doutorando em História pela Universidade Federal de Santa Maria (UFSM). Mestre em História pela UFSM. Bacharel e Licenciado em História pela UFSM. Técnico do Ministério Público Federal (MPF). Endereço Eletrônico: diego.o.souza@hotmail.com.
} 


\section{Resumen}

Este artículo trata de estudio de caso en la Policía Civil DOI/CODI/II Ejército y su relación con el desarrollo del campo de la justicia transicional en Brasil. Su principal objetivo es señalar las posibilidades de reforma las instituciones de seguridad en Brasil, que participan en la práctica sistemática de violaciónes de derechos humanos durante la dictadura cívico-militar, de la ejecución de tres delegados de la Policía Civil del Estado de São Paulo en DOI/CODI/II Ejército como agentes destacados de la represión política dirigida en los episodios de tortura, las desapariciones forzadas y muertes durante la década de 1970. La hipótesis desarrollada en el artículo trata de la manifestación de las ideas dominantes de la justicia en el juzgamiento de los crímenes cometidos por agentes de la represión política. Constituido través de la literatura y las fuentes documentales judiciales y extrajudiciales, parte del marco analítico de la justicia de transición con el fin de entender el juicio civil en primera instancia del caso de estudio. Entre las conclusiones de este artículo, pone de relieve la necesidad de promover medidas de justicia de transición, en relación con las purgas de agentes de la represión política, todavía perteneciente a la plantilla de la Policía Civil del Estado de São Paulo, así como desconstitución vínculos funcionales aquellos agentes represores con el Estado, que permitan a la reforma institucional de la Policía Civil de São Paulo, marcado por la impunidad de los agentes implicados en la práctica de crímenes de Estado durante la dictadura cívico-militar.

Palabras-clave: Policía civil. DOI/CODI/II Ejército. Justicia de Transición. Reforma de las instituciones.

\section{INTRODUÇÃO}

Este artigo tem como objetivo central acentuar o impacto da Ditadura Civil-Militar no Brasil sobre as instituições de segurança pública, em especial a Polícia Civil de São Paulo, ao enfatizar a necessidade de promoção de reformas institucionais no sentido de afastar os agentes envolvidos na prática de violações de direitos humanos durante 1964-1985. As possibilidades de reforma das instituições de segurança brasileira, envolvidas na prática sistemática de violações de direitos humanos durante a Ditadura Civil-Militar, são referidas a partir da atuação de delegados da Polícia Civil do Estado de São Paulo, no Destacamento de Operações de Informações do Centro de Operações de Defesa Interna do II Exército (DOI/CODI/II Exército) ${ }^{4}$, como destacados agentes da repressão política apontados em episódios de tortura, desaparecimentos forçados e mortes, durante as décadas de 1960/1970.

Desse modo, optou-se por se utilizar a interpretação do conceito de justiça de transição ou justiça transicional no campo da produção de conhecimento acerca do legado de violações sistemáticas e generalizadas de direitos humanos praticadas durante a Ditadura Civil-Militar. Neste sentido, ao analisar os processos de justiça transicional, ocorridos após as sucessivas restaurações da democracia ateniense (século $\mathrm{V}$ a. C), bem como tratar das

\footnotetext{
4 Para acompanhar os desdobramentos de pesquisa acadêmica voltada ao estudo da atuação repressiva do DOI/CODI/II Exército e as decorrentes iniciativas cíveis de reparação e responsabilização, promovidas pelo Ministério Público Federal, consultar: SOUZA, Diego Oliveira de. 2015. A Atuação Repressiva do DOI/CODI/II Exército: a visão militar e a justiça de transição nas iniciativas cíveis do Ministério Público Federal. Santa Maria. Dissertação (Mestrado em História). Universidade Federal de Santa Maria.
} 
medidas de retribuição e reparação adotadas na França após as restaurações da Monarquia dos Bourbons (1814-1815), Jon Elster revelou que a justiça transicional não é exclusiva dos regimes modernos e nem mesmo dos democráticos, sendo ela "composta pelos processos de juízos, expurgos e reparações que têm lugar no período de transição de um regime político para outro" (ELSTER, 2006, p. 15).

A hipótese desenvolvida no artigo trata da manifestação de ideias de justiça dominantes no julgamento dos crimes praticados por agentes da repressão política. Como bem lembra Rezende Martins, as ideias são um fator cultural de poder, diretamente relacionadas a um sistema de ação concreta, provocando impacto sobre a ação de indivíduos e de grupos e também sobre políticas e seus fundamentos (MARTINS, 2010, p. 26). Diante disso, conforme a filósofa Agnes Heller, importa notar que diferentes ideias de justiça são aplicadas a todas as sociedades, sendo que existem as ideias de justiça dominantes, as quais podem excluir a validade e aplicação de determinadas outras ideias operacionais numa sociedade (HELLER, 1998, p. 48). Desse modo, neste artigo, tais ideais dizem respeito à manutenção da impunidade dos crimes praticados pelos agentes estatais, tendo em vista que podem ser compreendidas de dois modos: pela compreensão da validade da Lei de Anistia de 1979 e seus efeitos sobre a conduta criminosa dos agentes estatais, ou então pelo reconhecimento da prescritibilidade das violações de direitos humanos praticadas pelos agentes repressores. No caso estudado, as ideias de justiça dominantes podem ser compreendidas de acordo ao primeiro modo anteriormente indicado.

De outro lado, contando com participação de membros da Polícia Civil e Militar do Estado de São Paulo, o DOI/CODI/II Exército, a partir de 1970, pode ser concebido como uma estrutura repressiva resultante do período da História da República Brasileira, no qual o Exército centralizou, ordenou e comandou as atividades de repressão política no País. Suas principais características de funcionamento dizem respeito à prática de crimes como prisão ilegal, tortura física e psicológica, desaparecimentos forçados, mortes e ocultação de cadáveres.

Por fim, segmentado em dois eixos centrais, o artigo aborda a composição variável do DOI/CODI/II Exército, demonstrando a união de forças repressivas para enfrentar a resistência política à Ditadura Civil-Militar. No primeiro eixo, traz levantamentos de informações acerca dos atores centrais do Caso Policiais Civis no DOI/CODI/II Exército, delineando as respectivas participações na repressão política. No segundo eixo, trata de 
medidas de justiça de transição, propostas pelo Ministério Público Federal, bem como aborda o julgamento cível do Caso Policiais Civis no DOI/CODI/II Exército, enfatizando o predomínio das ideias de justiça dominantes.

\section{OS ATORES DO CASO POLICIAIS CIVIS NO DOI/CODI/II EXÉRCITO}

Em setembro de 1970, surgiu nova orientação governamental para o combate à resistência política no Brasil. Tratava-se da Diretriz Presidencial de Segurança Interna, elaborada no governo do ditador Emílio Garrastazu Médici, a qual possibilitou a existência de 10 Destacamentos de Operações de Informações (DOIs), localizados nas cidades do Rio de Janeiro (DOI/CODI/I Exército), São Paulo (DOI/CODI/II Exército), Recife (DOI/CODI/IV Exército), Brasília (DOI/CODI/Comando Militar do Planalto), Curitiba (DOI/CODI/5a . Região Militar), Belo Horizonte (DOI/CODI/4a. Divisão de Exército), Salvador (DOI/CODI/6a . Região Militar), Belém (DOI/CODI/8 . Região Militar), Fortaleza (DOI/CODI/10ª . Região Militar) e Porto Alegre (DOI/CODI/III Exército) (USTRA, 1987, p. 68). Buscando justificativa para a realização do "combate à subversão", o ex-comandante do DOI/CODI/II Exército, Carlos Alberto Brilhante Ustra, definiu a reorganização da repressão política surgida por meio da referida Diretriz Presidencial:

Na primeira quinzena de setembro de 1970, a Presidência da República, em face aos problemas criados pelo terrorismo, expediu um documento que analisava em profundidade as consequências que poderiam advir dessa situação e definia o que deveria ser feito para impedir e neutralizar os movimentos subversivos. De acordo com essa Diretriz, em cada Comando de Exército, que hoje se denomina Comando Militar de Área, existiria: um Conselho de Defesa Interna (CONDI); um Centro de Operações de Defesa Interna (CODI); um Destacamento de Operações de Informações (DOI); todos sob a coordenação do próprio Comandante de cada Exército (USTRA, 1987, p. 67).

Em tempo, há de se mencionar que a ditadura de Emílio Garrastazu Médici ${ }^{5}$ foi marcada contraditoriamente pela intensa repressão política associada ao discurso de busca da "democracia e do desenvolvimento", os quais conforme suas palavras: "não se resume

\footnotetext{
5 Outro aspecto que merece atenção é que, antes de assinar a Diretriz Presidencial de Segurança Interna, o ditador Emílio Médici havia asseverado que não admitiria torturas em seu governo, chegando tal fato receber a matéria de capa da revista Veja. A matéria registrou o forte apelo da Ditadura para uma "adesão popular maciça e entusiástica" para vencer o "combate ao terrorismo", ao mesmo tempo em que noticiou o seguinte: "A violência está fora da lei. A violência da subversão nunca esteve dentro da lei. E a violência em nome da lei não é tolerada pelo presidente da República. Ao determinar a todos os órgãos de segurança do país que não admite o arbítrio, o presidente Garrastazu Médici inaugura nova etapa da Revolução". Consultar: Veja, Edição 65, 3 de dezembro de 1969. São Paulo: Editora Abril, p. 19.
} 
em iniciativas governamentais: são atos de vontade coletiva que cabe ao Governo coordenar e transformar em autênticos e efetivos objetivos nacionais" (MÉDICI, 1970, p. 11). Para auxiliar os esforços do governo na busca por seus objetivos, o Exército Brasileiro desenvolveu uma linha de ação repressiva que serviu de ensinamento para vários outros países latino-americanos:

Isso ocorreu com a criação dos CONDI, dos CODI e dos DOI e com o empenho de apenas 450 homens do seu efetivo, distribuídos aos DOI. O restante do pessoal dos DOI era complementado com os bravos e competentes membros das Polícias Civil e Militar dos Estados. $\boldsymbol{O}$ Exército, através dos Generais-de-Exército, Comandantes Militares de Área, centralizou, ordenou, comandou e se tornou responsável pela condução da Contra-subversão no país. Os DOI eram a força pronta para o combate, diretamente a eles subordinados (USTRA, 1987, p. 68, grifos nossos).

Desse modo, o Caso Policiais Civis no DOI-CODI/II Exército trata de Ação Civil Pública ajuizada pelo Ministério Público Federal (MPF), em São Paulo, a qual revela a atuação criminosa dos agentes da repressão Aparecido Laertes Calandra, David dos Santos Araujo e Dirceu Gravina, enquanto membros da Polícia Civil do Estado de São Paulo ${ }^{6}$ no desempenho de atividades sob o comando do II Exército Brasileiro. Para instruir a Ação Civil Pública relativa ao Caso Policiais Civis no DOI/CODI/II Exército, os Procuradores da República ${ }^{7}$, que propuseram esta iniciativa cível, realizaram o recolhimento de relatos de ex-presos políticos e de seus familiares vitimados pelos atos dos três policiais civis, além de reunirem depoimentos retirados de documentos como processos de auditorias militares, arquivos do DEOPS de São Paulo e livros, entre eles Brasil: Nunca Mais (1989) e o livrorelatório Direito à memória e à verdade (2007).

No enfretamento da participação direta em atos de tortura, abuso sexual, desaparecimentos forçados e homicídios, o MPF ingressou com a referida ação judicial

\footnotetext{
${ }^{6}$ Para Adriano Oliveira, questionar a presença dos direitos humanos e a suas possíveis violações, concentrandose meramente no âmbito da ação das polícias diante da sociedade, é uma abordagem limitada e ideológica. Entretanto, discorda-se dessa posição, pois mesmo que se reconheça os direitos humanos eventualmente violados dos agentes policiais é necessário que se promova a responsabilização e a reparação dos danos e prejuízos causados pela ação praticada em nome do Estado. De todo jeito, para uma abordagem que prioriza a violação dos direitos humanos perpetrados contra policiais ver o artigo de: OLIVEIRA, Adriano. 2007. Polícia e Direitos Humanos no Brasil. In: RATTON, José Luiz; BARROS, Marcelo. Polícia, Democracia e Sociedade. Rio de Janeiro: Lumen Juris, 2007.

7 São signatários desta ação judicial cível o Procurador Regional da República Marlon Alberto Weichert, as Procuradoras da República Eugênia Augusta Gonzaga, Adriana da Silva Fernandes, os Procuradores da República Luiz Costa, Sergio Gardenghi Suiama e o Procurador Regional dos Diretos do Cidadão em São Paulo, Jefferson Aparecido Dias.
} 
pedindo o afastamento imediato e a perda dos cargos e aposentadorias dos três delegados da Polícia Civil paulista mencionados. O grande foco dessa iniciativa ministerial é a responsabilização pela prática de torturas e mortes, enquanto membros das equipes funcionais do DOI/CODI/II Exército. A consequência imediata desta medida, como se verá adiante, se revela no esboço da possibilidade das reformas institucionais necessárias para a concretização da justiça transicional no Brasil.

A construção da síntese dos fatos envolvendo os 3 delegados da Polícia Civil do Estado de São Paulo, na prática de atividades repressivas no DOI/CODI/II Exército, demonstra a relevância dos testemunhos históricos enquanto instrumentos de prova judicial. Nesse sentido, percebe-se a importância dos testemunhos das vítimas da atuação repressiva do DOI/CODI/II Exército, enquanto prova documental utilizada na responsabilização por atos de violações de direitos humanos, praticadas durante a Ditadura Civil-Militar. Além disso, como enfatiza José Carlos Moreira da Silva Filho, o testemunho traz também a possibilidade de reconstrução simbólica do dano sofrido:

A figura intermediária, apta a manter em fluxo o contato entre história e
memória, é o testemunho. E isto é tanto mais verdade quando o passado
a ser re-presentado é o das grandes tragédias, violências e traumatismos
coletivos. O testemunho tem tanto um valor terapêutico para o
sobrevivente como um valor documental para a sociedade. Ele representa,
em primeiro lugar, a possibilidade de uma reconstrução simbólica diante
do trauma sofrido (SILVA FILHO, 2010, p. 210).

Há de se mencionar que o historiador Marc Bloch já havia percebido o valor documental do testemunho, mesmo diante dos possíveis erros do testemunho. Os erros do testemunho são reveladores de uma atmosfera social particular, a qual enfatiza o historiador:
No entanto, se os erros do testemunho fossem determinados, em última análise, apenas pelas fraquezas dos sentidos ou da atenção, o historiador só teria, em suma, que entregar seu estudo ao psicólogo. Mas, para além desses pequenos acidentes cerebrais, de natureza bastante comum, muitos deles remontam a causas muito mais significativas de uma atmosfera social particular. Eis por que assumem, frequentemente, por sua vez, um valor documental (BLOCH, 2002, p. 106).

Em seguimento, acerca das responsabilidades atribuídas pelos órgãos do MPF aos agentes da repressão, réus da Ação Civil Pública sobre o Caso Policiais Civis no DOI/CODI/II Exército, cumpre mencionar que o delegado Aparecido Laertes Calandra, na documentação e nos depoimentos colhidos pelo MPF, agia sob a alcunha de "capitão Ubirajara". O delegado Aparecido Laertes Calandra é apontado como tendo participado da tortura e do desaparecimento forçado do militante político Hiroaki Torigoe, da tortura, 
morte e da falsa versão de que o militante Carlos Nicolau Danielli fora morto em um tiroteio, da tortura do casal César e Maria Amélia Telles, além de participar da montagem da versão fantasiosa de que o jornalista Vladimir Herzog teria cometido suicídio nas celas do DOI/CODI/II Exército (BRASIL, 2010, fl. 07-12).

Em 8 de abril de 1992, a imprensa brasileira registrou o reconhecimento público do então delegado Aparecido Laertes Calandra, que prestava seus serviços naquela ocasião à Polícia Federal brasileira, como sendo o torturador de Nádia Lúcia Nascimento e Paulo de Tarso Vanucchi. Além disso, também houve repercussão das seguintes atividades do delegado Calandra:

O dono de uma das sombras mais sinistras dos porões do regime militar ganhou um rosto, nome e sobrenome na semana passada. Na quarta-feira, o Jornal do Brasil revelou que o 'capitão Ubirajara', torturador do DOICodi, é o delegado Aparecido Laertes Calandra. Ele trabalha no $18^{\circ}$ andar do prédio da Polícia Federal em São Paulo, em uma sala ao lado do gabinete do superintendente Marco Antônio Veronezzi. Está encostado, sem função definida, segundo seus colegas. Sua sombra, porém, deixou marcas em outro endereço - o n 921 da Rua Tutóia, onde funcionou nos anos 70 a Operação Bandeirantes, Oban, e seu sucedâneo o DOI-Codi. (...) Delegado estadual, trabalhou nos anos 70 no extinto Dops, lotado no DOI-Codi entre 1972 e 1976. Foi para a PF em 1983, levado com outros dezoito delegados por seu superior, Romeu Tuma, que assumiu a superintendência da PF paulista. Calandra cuidou então do arquivo do Dops, levado para a PF na época e devolvido em janeiro [1992] passado para o Estado, com acréscimos e sumiços. ${ }^{8}$

De outra ponta, o rol das acusações de violações de direitos humanos praticadas pelo delegado David dos Santos Araujo envolve as vítimas Joaquim Alencar de Seixas, Ivan Akselrud Seixas, Fanny Akselrud de Seixas, Ieda Akselrud de Seixas, Iara Akselrud de Seixas e Milton Tavares Campos (BRASIL, 2010, fl. 12-17). Do testemunho histórico de Ivan Seixas, militante político preso aos 16 anos junto com o pai, Joaquim Alencar de Seixas, este torturado e morto nas dependências do DOI-CODI/II Exército, surge a identificação do delegado David dos Santos Araujo, como sendo o "capitão Lisboa", codinome utilizado na época dos fatos apurados na investigação ministerial. Como forma de pressão, os policiais, dentre os quais se encontrava David dos Santos Araujo, levaram Ivan Seixas para uma área próxima ao Parque do Estado de São Paulo, então deserta, e simularam seu fuzilamento.

\footnotetext{
8 Para maiores informações sobre as atividades do delegado da Polícia Civil de São Paulo, Aparecido Laertes Calandra, junto à Polícia Federal, ver a reportagem: $O$ algoz sai da sombra: Delegado da Polícia Federal é o capitão Ubirajara, um dos mais temidos torturadores do DOI-Codi Paulista. Revista Veja, Edição 1229, 8 abr. 1992, São Paulo: Editora Abril, p. 61, interpolações nossas.
} 
Depois, o colocaram em uma viatura e foi apresentada a ele a edição da Folha da Tarde em que a manchete anunciava que seu pai fora morto pelas forças repressivas. Ao chegar no DOI/CODI/II Exército, seu pai ainda estava vivo. ${ }^{9}$ Do relato de Ivan Seixas, destaca-se que os agentes da repressão “(...) algumas vezes, chegavam a se identificar. Em uma ocasião, ao transportar Seixas numa viatura, Araújo voltou-se para ele, mostrou a carteira funcional e disse: 'sou o delegado David dos Santos Araújo e não tenho medo de você' (BRASIL, 2010, fl. 16).

Ademais, o terceiro delegado da Polícia Civil de São Paulo, com passagem pelo DOI/CODI/II Exército, réu na ACP Policiais Civis no DOI/CODI/II Exército é o delegado Dirceu Gravina, o qual é motivo de destaque tendo em vista que em ao desempenhar suas atividades naquele organismo repressivo, sob o comando do II Exército Brasileiro, é tido como:

O mais jovem dos três policiais e até hoje no cargo de delegado da Polícia Civil, Dirceu Gravina era chamado pelos colegas de JC - uma alusão à Jesus Cristo por, à época, com pouco mais de 20 anos, manter os cabelos compridos e lisos e usar crucifixo - e é lembrado nos relatos por sua violência e sadismo (ASCOM-PRR3, 2010, p. 14).

O delegado Dirceu Gravina, entre muitos casos de violações direitos humanos, surge com maior destaque no caso do desaparecimento forçado de Aluízio Palhano Pedreira Ferreira, tendo em vista que:

Gravina ainda é apontado como o último a torturar o preso político Aluízio Palhano Pedreira Ferreira, dizendo a outro preso, após Palhano parar de gritar de dor, que sua equipe tinha acabado de matar o colega: 'Agora vai ser você!', ameaçou Gravina na sequência. Desde então, nunca mais se teve notícias de Aluízio, desaparecido até hoje. Também foram vítimas de Gravina os presos políticos Manoel Henrique Ferreira e Artur Scavone (ASCOM-PRR3, 2010, p. 15).

No livro-relatório da Secretaria Especial de Direitos Humanos da Presidência da República, Direito à memória e à verdade, constam as seguintes informações sobre os abusos de direitos humanos praticados contra Aluízio Palhano Pedreira Ferreira:

O nome de Aluízio consta da lista de desaparecidos políticos anexa à Lei n ${ }^{\circ}$ 9.140/95, tendo sido preso em 09/05/1971 em São Paulo. (...) Sua

\footnotetext{
9 A partir do caso do jornal Folha da Tarde, da empresa Folba da Manhã, Beatriz Kushnir permite que seja verificada a colaboração jornalística com a Ditadura Civil-Militar. Em 1969, o referido jornal recebeu a Direção do repórter que era policial, Antônio Aggio, o qual trouxe consigo outros policiais para a redação do jornal. Com isso, a Folha da Tarde tornou-se o "Diário Oficial da OBAN", sendo que os jornalistas que cobriam a área policial passaram a trocar intencionalmente a narrativa de um acontecimento pela publicação de versões que corroborassem com o ideário oficial da Ditadura Civil-Militar. Para maiores detalhes consultar: KUSHNIR, 2004, p. 249-264.
} 
prisão e morte foram denunciadas pelo preso político Altino Rodrigues Dantas Jr., em carta enviada do Presídio Romão Gomes, de São Paulo, em $1^{\circ}$ de agosto de 1978, ao general Rodrigo Octávio Jordão Ramos, ministro do STM que vinha, naquele tribunal superior, adotando corajoso posicionamento contrário às violações de direitos humanos já denunciadas há vários anos. A prisão de Palhano também foi testemunhada por outros presos políticos, entre eles o militante do MR-8 Nelson Rodrigues Filho, filho do conhecido dramaturgo brasileiro, que esteve com ele no DOICODI do Rio de Janeiro (BRASIL, 2007, p. 411-413).

Contudo, após trazer informações acerca dos atores centrais do Caso Policiais Civis no DOI/CODI/II Exército, delineando as respectivas participações na repressão política daquele período, na próxima seção deste artigo, serão apresentadas as medidas de justiça de transição relacionadas à reforma das instituições de segurança do Estado, extraídas da Ação Civil Pública relativa ao Caso estudado.

\section{AS MEDIDAS DE JUSTIÇA DE TRANSIÇÃO E O JULGAMENTO DO CASO POLICIAIS CIVIS NO DOI/CODI/II EXÉRCITO}

Justamente em vista das violações sistemáticas de direitos humanos, envolvendo os três delegados da Polícia Civil do Estado de São Paulo, na Ação Civil Pública relativa ao Caso Policiais Civis no DOI/CODI/II Exército, o pedido realizado pelo MPF quando do julgamento daquela iniciativa cível, foi no sentido da realização das seguintes medidas amparadas nas dimensões da justiça de transição, de acordo com a Quadro 1:

Quadro 1 - Caso Policiais Civis no DOI/CODI/II Exército-medidas de justiça de transição

\begin{tabular}{|c|c|}
\hline $\begin{array}{c}\text { Pilares justiça de } \\
\text { transição }\end{array}$ & Proposições MPF \\
\hline 1. Declarar a existência de relação jurídica entre APARECIDO \\
LAERTES CALANDRA, DAVID DOS SANTOS ARAUJO e \\
DIRCEU GRAVINA e a sociedade brasileira, bem como entre \\
esses e as vítimas do DOI/CODI do II Exército e/ou da Polícia \\
Civil do Estado de São Paulo (inclusive as referidas nos itens 3 e 6 \\
desta inicial), ou seus familiares, em razão das \\
responsabilidades pessoais dos réus pelas graves violações \\
aos direitos humanos perpetradas durante o período em que \\
serviram nesses órgãos.
\end{tabular}




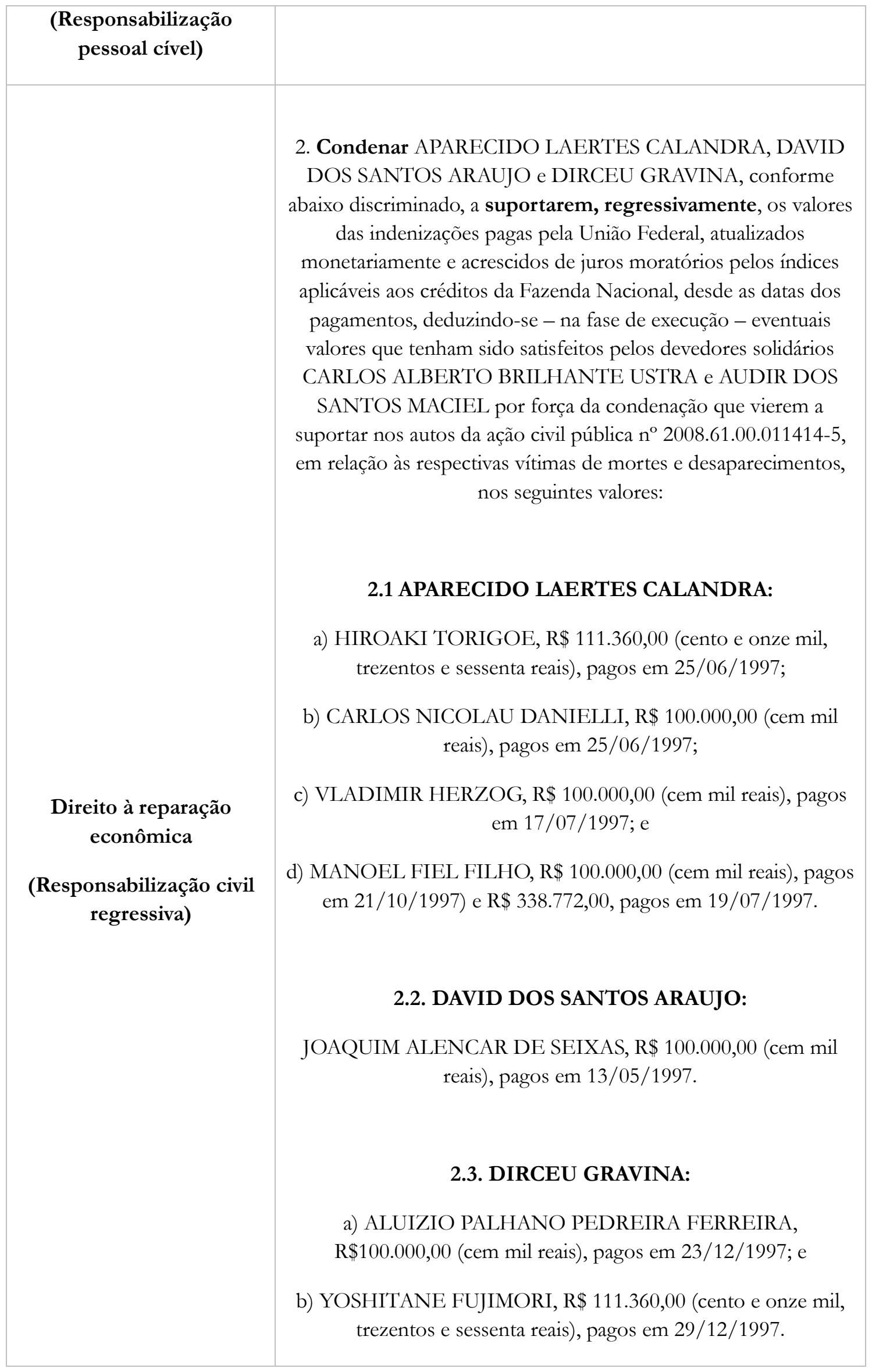




\begin{tabular}{|c|c|}
\hline $\begin{array}{l}\text { Direito à reparação } \\
\text { econômica } \\
\text { (Responsabilização civil } \\
\text { regressiva) }\end{array}$ & $\begin{array}{l}\text { 3. Condenar APARECIDO LAERTES CALANDRA, DAVID } \\
\text { DOS SANTOS ARAUJO e DIRCEU GRAVINA } \\
\text { a suportarem, regressivamente, as indenizações pagas pela } \\
\text { União Federal em razão das violências sofridas, nos termos da Lei } \\
\mathrm{n}^{\circ} \text { 10.559/02, às vítimas listadas no item } 6 \text { desta petição inicial, }{ }^{10} \\
\text { bem como àquelas que vierem a ser indicadas em fase instrutória, } \\
\text { nos montantes que vierem a ser informados pela Comissão de } \\
\text { Anistia do Ministério da Justiça, devidamente atualizados } \\
\text { monetariamente e acrescidos de juros moratórios pelos índices } \\
\text { aplicáveis aos créditos da Fazenda Nacional, desde as datas dos } \\
\text { pagamentos respectivos. }\end{array}$ \\
\hline \multirow[t]{2}{*}{$\begin{array}{l}\text { Direito à reparação } \\
\text { econômica }\end{array}$} & $\begin{array}{l}\text { 4. Condenar APARECIDO LAERTES CALANDRA, DAVID } \\
\text { DOS SANTOS ARAUJO e DIRCEU GRAVINA a repararem } \\
\text { os danos morais coletivos mediante pagamento de indenização } \\
\text { a ser revertida ao Fundo de Direitos Difusos, em montante a ser } \\
\text { fixado na sentença, ou outra providência razoável. }\end{array}$ \\
\hline & $\begin{array}{l}\text { 5. Condenar APARECIDO LAERTES CALANDRA, DAVID } \\
\text { DOS SANTOS ARAUJO e DIRCEU GRAVINA à perda das } \\
\text { funções e cargos públicos, efetivos ou comissionados, que }\end{array}$ \\
\hline
\end{tabular}

${ }^{10}$ São as seguintes vítimas: $\mathrm{i}$ - Réu Aparecido Laertes Calandra: 1) Hiroaki Torigoe (tortura e desaparecimento); 2) Carlos Nicolau Danielli (tortura e homicídio); 3) Maria Amélia de Almeida Teles (tortura); 4) Cesar Augusto Teles (tortura); 5) Janaína Teles (tortura); 6) Edson Luís Teles (tortura); 7) Manoel Henrique Ferreira (tortura); 8) Artur Machado Scavone (tortura); 9) Paulo Vannuchi (tortura); 10) Nádia Lúcia Nascimento (tortura); 11) Nilmário Miranda (tortura); 12) Vladimir Herzog (tortura e homicídio); 13) Manoel Fiel Filho (tortura e homicídio) 14) Pierino Gargano (tortura) 15) Companheira de Pierino Gargano (tortura); ii - Réu David Dos Santos Araujo: 1) Joaquim Alencar de Seixas (tortura e homicídio); 2) Ivan Akselrud Seixas (tortura); 3) Fanny Seixas (tortura); 4) Ieda Seixas (tortura); 5) Iara Seixas (tortura); 6) Milton Tavares Campos (tortura); iii - réu Dirceu Gravina: 1) Lenira Machado (tortura); 2) Aluizio Palhano Pedreira Ferreira (tortura e desaparecimento); 3) Altino Rodrigues Dantas Junior (tortura); 4) Manoel Henrique Ferreira (tortura); 5) Artur Machado Scavone (tortura); 6) Yoshitane Fujimore (tortura e desaparecimento). Consultar: BRASIL, 2010, p. 41-42, grifos nossos. 
Reforma das instituições

(Expurgos)

Reforma das instituições

(Penalização) estejam eventualmente exercendo na Administração direta ou indireta de qualquer ente federativo, bem como a não mais serem investidos em nova função pública, de qualquer natureza.

6. Condenar APARECIDO LAERTES CALANDRA, DAVID DOS SANTOS ARAUJO e DIRCEU GRAVINA à perda dos benefícios de aposentadoria ou inatividade que estejam percebendo do Estado de São Paulo, independentemente da data em que foram concedidos.
Reforma das instituições

(Expurgos)
7. Desconstituir os vínculos existentes entre APARECIDO LAERTES CALANDRA, DAVID DOS SANTOS ARAUJO e DIRCEU GRAVINA e o Estado de São Paulo, relativamente às investiduras nos cargos públicos que ainda exerçam, bem como, conforme o caso, os vínculos relativos à percepção de benefícios de aposentadoria ou inatividade.

8. Condenar a União Federal e o Estado de São Paulo a repararem os danos imateriais causados pelas condutas de seus agentes durante a repressão aos dissidentes políticos da Ditadura

Civil-Militar mediante pedido de desculpas formal a toda a população brasileira, com a citação dos casos específicos reconhecidos na presente ação, a ser preferencialmente proferido pelas respectivas chefias de governo, divulgado em mensagem veiculada ao menos em dois jornais de grande circulação no Estado de São Paulo, com espaço equivalente a meia página, por

Direito à reparação simbólica no mínimo 2 domingos seguidos, sem prejuízo de outras providências que esse Juízo considere pertinente. 
9. Condenar o Estado de São Paulo a revelar os nomes e cargos dos seus servidores da Administração direta ou indireta que, em qualquer tempo, foram requisitados, designados ou cedidos, sob qualquer título ou forma, para atuar no DOI/CODI, especificando os períodos de tempo em que exerceram funções naquele destacamento militar. Requer, finalmente, a fixação de multa diária na hipótese de descumprimento do disposto nos itens 8 e 9 do pedido, em valor que se pede não seja inferior a

Direito à memória e à $\mathrm{R} \$ 10.000,00$ (dez mil reais). verdade

Fonte: Informações extraídas da iniciativa cível do MPF relativa ao Caso Policiais Civis no DOI-CODI/SP. Consultar: BRASIL, 2010, p. 52-54, grifos nossos.

Para alcançar o objetivo deste artigo, interessa as três medidas propostas pelo MPF que ilustram possibilidades de reforma das instituições de segurança do Estado, através de medidas judiciais cíveis. Nesse sentido, a condenação dos 3 delegados da Polícia Civil do Estado de São Paulo à perda das funções e cargos públicos, efetivos ou comissionados, que estejam eventualmente exercendo na Administração direta ou indireta de qualquer ente federativo, bem como a não mais serem investidos em nova função pública de qualquer natureza é uma medida exemplar que tem seu efeito reforçado quando associada à perda dos benefícios de aposentadoria ou inatividade, e também à desconstituição dos vínculos existentes entre aqueles agentes da repressão e o Estado de São Paulo. Portanto, o afastamento de tais agentes do serviço público trata-se de medida que permite a reforma das instituições de segurança por meio da promoção de expurgos de agentes envolvidos em crimes do Estado durante a Ditadura Civil-Militar.

De todo modo, em 21 de março de 2011, a Juíza Federal Diana Brunstein, da $7^{\text {a }}$ Vara Federal Cível de São Paulo, ao promover o julgamento do Caso Policiais Civis no DOI/CODI/II Exército se utilizou de interpretação atécnica da Lei de Anistia, pois a considerou como instrumento normativo válido para impedir a responsabilização dos três policiais civis. Nas palavras da magistrada, as ideias de justiça dominantes são perceptíveis no momento em que há retomada do mito da anistia "ampla, geral e irrestrita", ficando assim registrado:

Colaciona o autor na petição inicial diversos relatos de presos que alegam terem sofrido violência por parte dos réus APARECIDO LAERTES 
CALANDRA, DAVID DOS SANTOS ARAÚJO e DIRCEU GRAVINA. Portanto, a demanda diz respeito a fatos ocorridos nas décadas de 1960 e 1970, relativamente aos quais foi editada a Lei n 6.683, de 28 de agosto de 1979, (...) verifica-se que o pedido formulado não merece prosperar, uma vez que pretende o autor a responsabilização dos réus por fatos que foram objeto de anistia "ampla e geral", o que afasta a tese da responsabilidade civil por ato ilícito, já que a Lei da Anistia impede qualquer condenação dos agentes do Estado eventualmente envolvidos em atividades que pudessem ser consideradas criminosas. Assim, se não há crime, na forma da Lei n 6.683/79, não há como condenar os réus ao pagamento das indenizações ora postuladas, nem tampouco declarar a existência de relação jurídica tendente a responsabilizá-los por eventuais atos praticados sob o "regime de exceção". (...) Quanto ao pedido de desculpas públicas e reconhecimento dos fatos narrados na petição inicial pelos chefes do Poder Executivo da União Federal e do Estado de São Paulo, tal pleito encontra-se prejudicado diante da edição da Lei $n$ 10.559/2002 que, regulamentando o artigo 8 do Ato das Disposições Constitucionais Transitórias, estabeleceu reparação econômica de caráter indenizatório ao anistiado político, o que equivale ao reconhecimento público acerca dos fatos ocorridos no período (...) Diante do exposto, rejeito os pedidos formulados JULGO IMPROCEDENTE a ação, razão pela qual a extingo o processo com exame do mérito, nos termos do Artigo 269, inciso I, do Código de Processo Civil (BRASIL, 2011b, fls.1388-verso e fls. 1391-1392).

O MPF, inconformado com a decisão da Juíza da $7^{a}$ Vara Federal Cível de São Paulo, formulou recurso contra a sentença de 21 de março de 2011. Por meio de farta argumentação contrária à consideração de que a Lei de Anistia impede qualquer tipo de pretensão, inclusive não penal, diante dos crimes da Ditadura Civil-Militar, o MPF enfatizou o caráter de sua iniciativa cível:

[...] visando espancar qualquer dúvida sobre a linha que orienta a atuação do Ministério Público em ações dessa natureza, vale lembrar que a tortura no Brasil, durante o regime militar, não é uma invenção ou um devaneio de alguns poucos brasileiros e brasileiras. Infelizmente a tortura existiu naquele período, de maneira generalizada e extremamente cruel. Há que se entender a real dimensão desses fatos os quais têm sido esquecidos pelas autoridades no presente e o esquecimento é a pior forma de se lidar com o tema, gerando uma gravíssima omissão. Não se trata de defender esta ou aquela ideologia, mas da necessidade de se romper com essa linha de inércia. A obrigação do Ministério Público Federal de postular a responsabilização de perpetradores de tortura ou qualquer outra grave violação aos direitos humanos independe de coloridos ou filiações ideológicas. A instituição age de acordo com a sua missão constitucional e fossem os atos apontados nesta ação praticados por pessoas de outra inclinação política, a postura institucional seria exatamente a mesma (BRASIL, 2011a, fls. 16-17).

Contudo, o processo judicial foi remetido ao Tribunal Regional Federal da $3^{\text {a }}$ Região, em 30 de agosto de 2011, para o julgamento da apelação realizada pelo MPF. Os autos judiciais foram distribuídos à $3^{\text {a }}$ Turma daquele Tribunal Regional Federal, sendo que desde 
14 de novembro de 2012, encontravam-se conclusos ao Relator Desembargador Federal Marcio Moraes. Entretanto, em 25 de maio de 2015, houve a redistribuição do processo judicial referido ao Gabinete do Desembargador Federal Nelton dos Santos. Com isso, até o momento da finalização desse artigo, a Ação Civil Pública referente ao Caso Policiais Civis no DOI/CODI/SP, após a sentença da $7^{a}$ Vara Federal Cível de São Paulo que a julgou improcedente, ainda aguardava o posicionamento do Tribunal Regional Federal da $3^{\text {a }}$ Região sobre o recurso interposto pelo órgão ministerial.

\section{CONSIDERAÇÕES FINAIS}

Nesse artigo, levando-se em consideração o impacto das Ditaduras sobre a América Latina, em especial a luta por memória-verdade-justiça, mereceu destaque o Caso Policiais Civis no DOI/CODI/II Exército, por apresentar entre as medidas de justiça de transição, consideradas pertinentes para reparar e responsabilizar a conduta dos agentes da repressão investigados, a necessidade de se reformar as instituições de segurança.

Ademais, o Caso Policiais Civis no DOI/CODI/II Exército, do ponto de vista da construção do conhecimento científico acerca do período da Ditadura Civil-Militar, através da revelação das atividades criminosas dos agentes da repressão Aparecido Laertes Calandra, David dos Santos Araujo e Dirceu Gravina, permitiu delimitar o impacto do legado da Ditadura Civil-Militar sobre as atividades da Polícia Civil de São Paulo. Dentre outras possibilidades, o impacto pode ser percebido pela manutenção da impunidade de seus agentes envolvidos na prática de abusos de direitos humanos contra perseguidos políticos, durante o final da década de 1960 e início da década de 1970.

Em atenção à hipótese elaborada no presente artigo, o julgamento em primeira instância do Caso estudado revelou a manifestação de ideais de justiça dominantes que dizem respeito diretamente à manutenção da impunidade dos crimes praticados pelos agentes estatais durante a Ditadura CivilMilitar. Isso ocorreu, tendo em vista que, em mais uma oportunidade, foi alegada a compreensão da validade da aplicação e interpretação da Lei de Anistia de 1979 e seus efeitos sobre a conduta criminosa dos agentes repressores estatais.

Contudo, as medidas de justiça de transição estabelecidas no Caso Policiais Civis no DOI/CODI/II Exército, em especial aquelas que dizem respeito aos expurgos de agentes da repressão dos quadros da Polícia Civil do Estado de São Paulo ou mesmo à 
desconstituição de vínculos com o Estado, são alternativas para se possibilitar a reforma das instituições estatais de segurança, marcadas pela impunidade diante dos crimes de Estado, mesmo diante de interpretações atécnicas da Lei de Anistia de 1979, as quais vislumbram efeitos cíveis para esta lei, como a exposta no julgamento, em primeira instância, do caso estudado.

\section{REFERÊNCIAS}

ARQUIDIOCESE DE SÃO PAULO. 1989. Brasil Nunca Mais. 22 ed. Rio de Janeiro: Vozes.

Assessoria de Comunicação Social - Procuradoria Regional da República da $3^{a}$ Região (ASCOM-PRR3). 2010. Ditadura: MPF move ação para que policiais civis acusados de torturas e mortes no Doi/Codi percam cargo e aposentadoria. PRR3 em Revista. n. 6. Disponível em: [http://www.prr3.mpf.mp.br/component/remository/Publica $\%$ C3 $\%$ A7\% $\%$ C3 $\%$ B 5 es $/$ PRR 3-em-Revista-n\%C2\%BA-06/]. Acesso em: [21 set. 14].

BLOCH, Marc Leopold Benjamin. 2002. Apologia da história on o oficio de historiador. Rio de Janeiro: Zahar.

BRASIL. Secretaria Especial de Direitos Humanos. Comissão Especial sobre Mortos e Desaparecidos Políticos. 2007. Direito à memória e à verdade. Brasília: Secretaria Especial de Direitos Humanos.

ELSTER, Jon. 2006. Rendición de cuentas: la justicia transicional em perspectiva histórica. Buenos Aires: Katz.

HELLER, Agnes. 1998. Além da justiça. Rio de Janeiro: Civilização Brasileira.

KUSHNIR, Beatriz. 2004. Cães de guarda: entre jornalistas e censores. In: REIS FILHO, Daniel Aarão; RIDENTI, Marcelo; MOTTA, Rodrigo Patto Sá (orgs.). O Golpe e a Ditadura Militar. 40 anos depois (1964-2004). Bauru. Ed. da USC.

MARTINS, Estevão C. de Rezende. 2010. Cultura e poder. 2 ed. São Paulo: Saraiva.

MÉDICI, Emílio Garrastazu. 1970. O jogo da verdade. 2 ed. Brasília: Departamento de Imprensa Nacional.

OLIVEIRA, Adriano. 2007. Polícia e Direitos Humanos no Brasil. In: RATTON, José Luiz; BARROS, Marcelo. Polícia, Democracia e Sociedade. Rio de Janeiro: Lumen Juris.

SILVA FILHO, José Carlos Moreira da. 2010. Dever de memória e a construção da história viva: a atuação da Comissão de Anistia do Brasil na concretização do direito à memória e à verdade. In: SANTOS, Boaventura de Sousa; ABRÃO, Paulo; SANTOS, Cecília Macdowell dos; TORELLY, Marcelo Dalmás (orgs.). Repressão e memória política no contexto ibero-brasileiro: estudos sobre Brasil, Guatemala, Moçambique, Peru e Portugal. Brasília: Ministério da Justiça, Comissão de Anistia; Portugal: Universidade de Coimbra, Centro de Estudos Sociais. 
SOUZA, Diego Oliveira de. 2015. A Atuação Repressiva do DOI/CODI/II Exército: a visão militar e a justiça de transição nas iniciativas cíveis do Ministério Público Federal. Santa Maria. Dissertação (Mestrado em História). Universidade Federal de Santa Maria.

USTRA, Carlos Alberto Brilhante. 1987. Rompendo o silêncio: OBAN, DOI/CODI. 29 set. 70 24 jan. 74. Brasília: Editerra.

\section{FONTES PESQUISADAS}

BRASIL. Ministério Público Federal. Procuradoria da República no Estado de São Paulo. Petição inicial na Ação Civil Pública n 0018372-59.2010.4.03.6100. São Paulo, 30 ago. 2010. Caso Policiais Civis no DOI-CODI/SP. Disponível em: [www.prr3.mpf.gov.br]. Acesso em: [21 set. 2014].

BRASIL. Ministério Público Federal. Procuradoria da República no Estado de São Paulo. Apelação na Ação Civil Pública nº 0018372-59.2010.4.03.6100. São Paulo, 29 jun. 2011a. Caso Policiais Civis no DOI-CODI/SP. Disponível em: [www.prr3.mpf.gov.br]. Acesso em: [21 set. 2014].

BRASIL. $7^{\text {a }}$ Vara da Justiça Federal em São Paulo. Ação Civil Pública n ${ }^{\circ} 0018372-$ 59.2010.4.03.6100. Autor: Ministério Público Federal. Réus: União, Estado de São Paulo, Aparecido Laertes Calandra, David dos Santos Araujo, Dirceu Gravina. Juíza Federal Diana Brunstein. Sentença Tipo A. São Paulo, 21 mar. 2011b. Disponível em: [www.prr3.mpf.gov.br]. Acesso em: [21 set. 2014].

Revista Veja, Edição 65, 3 dez. 1969. São Paulo: Editora Abril.

Revista Veja, Edição 1229, 8 abr. 1992, São Paulo: Editora Abril. 